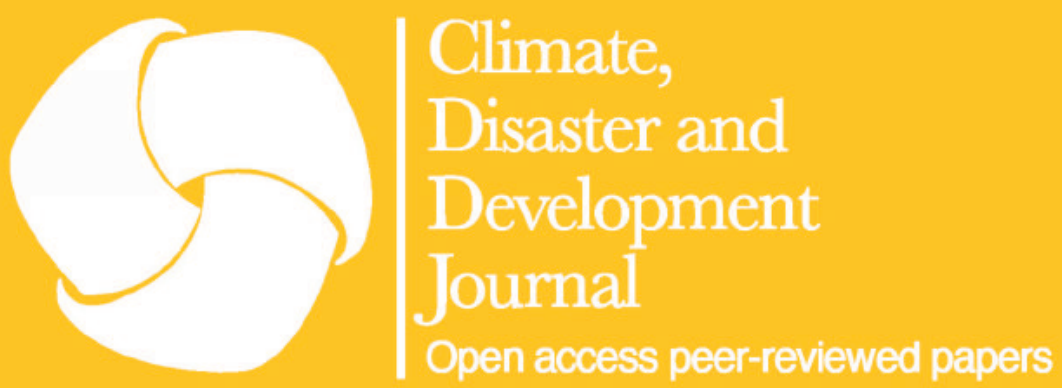

\title{
The impacts of Typhoon Haiyan in the Philippines: Implications to land use planning
}

\author{
Carlos Tito Santos ${ }^{1,2} \cdot$ Luigi Toda $^{1,3} \cdot$ Justine Ravi Orduña ${ }^{1,4} \cdot$ Filipe Duarte Santos $^{2} \cdot$ João Ferrão $^{5}$ \\ ${ }^{1}$ Oscar M. Lopez Center for Climate Change Adaptation and Disaster Risk Management Foundation, Inc. \\ ${ }^{2}$ Faculty of Sciences, University of Lisbon \\ ${ }^{3}$ Australian National University \\ ${ }^{4}$ University of the Philippines Diliman \\ ${ }^{5}$ Institute of Social Sciences, University of Lisbon
}

Received: 20 April 2015 / Accepted: 15 December 2015 / Published online: 31 December 2015

\begin{abstract}
Recent extreme weather events have brought devastating impacts on people's lives and infrastructure in many parts of the world. The scale of the impact of Typhoon Haiyan in the Philippines revealed a high degree of vulnerability and exposure of coastal communities to extreme events in a region that is regularly hit by tropical cyclones. This paper is based on initial assessment of the immediate impacts of Typhoon Haiyan. It was conducted in the cities of Tacloban and Ormoc and in the municipality of Palo, which were heavily affected by the impacts of Haiyan. Vulnerability to typhoon-related hazards and impacts of climate change is considered to be one of the major issues affecting land use in these areas. This paper analyzed existing legal framework and how climate change adaptation (CCA) and disaster risk reduction (DRR) can be incorporated in policies and plans such as the Comprehensive Land Use Plan (CLUP). It also examined the roles and responsibilities of both central and local governments in the Philippines in terms of land use planning and disaster mitigation strategies and their implications towards the future development of climate resilient communities, particularly in the context of a contentious resettlement process as a result of the application of a hazard-based zoning process. The vulnerability of the Philippines to climate change and natural disasters calls for risk reduction measures that decrease the exposure through land use planning, hazard-based zoning, climate resilient building codes and retrofitting as well as innovative financial incentives. These CCA and DRR measures should be mainstreamed into the local government plans through the CLUP and followed by an effective implementation. However, a key challenge to local decision-makers in these Typhoon Haiyan-affected areas is how to incorporate a range of possible vulnerabilities driven by changing landscape, infrastructure, and socioeconomic conditions in land use planning.
\end{abstract}

Keywords: Typhoon Haiyan $\cdot$ Philippines $\cdot$ land use planning $\cdot$ climate change $\cdot$ disaster risk reduction

\section{Corresponding Author:}

Carlos Tito Santos

Oscar M. Lopez Center for Climate Change Adaptation and Disaster Risk Management Foundation, Inc.

University of Lisbon

carlos.tito.santos@gmail.com 


\section{Introduction}

The Fifth Assessment Report of the Intergovernmental Panel on Climate Change (IPCC) concluded that "impacts from recent climate-related extremes, such as heat waves, droughts, floods, cyclones, and wildfires reveal significant vulnerability and exposure of some ecosystems and many human systems to current climate variability (very high confidence)" (IPCC, 2014a, p. 53). The same report emphasizes that "in urban areas, climate change is projected to increase risks for people, assets, economies and ecosystems, including risks from heat stress, storms and extreme precipitation, inland and coastal flooding, landslides, air pollution, drought, water scarcity, sea-level rise, and storm surges (very high confidence)" (IPCC, 2014a, p. 69).

Recent extreme weather events were responsible for some of the most destructive impacts in years such as Hurricane Katrina in 2005, Cyclone Nargis in 2008, Hurricane Sandy in 2012, and Typhoon Haiyan in 2013. In the U.S.A., tropical cyclones pose a significant threat to coastal population, mostly not due to extreme winds but to the associated storm surge most often combined with fresh water flooding due to extreme rainfall (Rappaport, 2000).

Asia and the Pacific is the region more affected by the impact of extreme weather events, coupled with high level of exposure to the impacts by exceedingly vulnerable populations who are extremely poor and marginalized (Asian Development Bank [ADB], 2012). The disaster risk in cities increases through high population density, deficient urban planning, and poor infrastructure (Chughtai, 2013). Due to poverty, people often have no alternatives but to live in the lowlying coastal areas, riverbanks, flood plains, dangerous slopes, and degraded urban environments where the impacts of extreme weather are more severe (ADB, 2012).

In the Philippines, the consequences of extreme weather events have been overwhelming in terms of human lives, ecosystems, and infrastructure destruction, with the national economy and local governments often taking many years to recover.

Planners are being faced with the challenges of growing population, limited appropriate space, and the risks from natural disasters (Sutanta, Rajabifard, \& Bishop, 2010). It is important to prepare cities and municipalities to deal with cyclic natural hazards to enable them to address the transformations that result from climate variability and change while developing innovative solutions in spatial planning (Costa, 2011).

This paper analyzed the issues facing central and local governments in the Philippines in terms of the impacts of climate variability and change in the context of the impact of tropical cyclone Haiyan and the implications for long-term land use planning, zoning, and building regulations in the overall climate change adaptation (CCA) and disaster risk reduction and management (DRRM) process.

Typhoon Haiyan, also known as "Yolanda" in the Philippines, made landfall over Guiuan, Eastern Samar in the Visayas region on the morning of November 8, 2013 (National Disaster Risk Reduction and Management Council [NDRRMC], 2014b). It brought maximum sustained winds of $315 \mathrm{kph}$ with gusts reaching $380 \mathrm{kph}$ with heavy rains (Mullen, 2013) and caused a 5-meter storm surge. This category 5 typhoon is considered as one of the strongest tropical cyclones ever recorded globally (United Nations Office for the Coordination of Humanitarian Affairs[UNOCHA], 2013). Haiyan left 6,300 dead, 1,061 missing, and 28,689 injured and affected 12,139 barangays (villages), 44 provinces, 591 municipalities, and 57 cities (NDRRMC, 2014b, 2014c). According to Delfino, Carlos, David, Lasco, and Juanico (2015), Haiyan also caused damages to the different ecosystems found in the region (e.g., mangroves), affecting the delivery of important ecosystem services such as livelihood and coastal protection.

It was reported that approximately 12.2 million people were affected by this catastrophe, leaving 489,613 houses completely destroyed and 595,149 that are partially damaged (NDRRMC, 2014a; National Economic Development Authority [NEDA], 2013). Typhoon Haiyan caused an overall estimated cost "of damaged physical assets - both public and private-at PhP424 billion (3.7 percent of GDP)" (NEDA, 2014 cited by the World Bank, 2014, p. 37).

\section{Methodology}

This study was based on desk reviews with household surveys and key informant interviews and expert consultations, focusing on land use-related factors of vulnerability. To assess the conditions and the situation on the concerned local government units (LGUs), key informant interviews with their mayors, city or municipal planning and development officers, city and municipal engineer's office, local social welfare and development officers, local DRRM officers, Department of the Interior and Local Government (DILG) officers, and barangay chairpersons were conducted. Experts on the field of land use planning and policy interpretation (the Commissioner of Housing and Land Use Regulatory Board, and the Dean of Ateneo School of Government) were also consulted.

The household surveys were conducted to assess infrastructure guidance and services, land tenure status, public infrastructure conditions, and housing materials, indicators that influence land use planning. This 
assessment also considered the risk factors associated with the tropical cyclones.

Documents such as the revised Comprehensive Land Use Plan (CLUP) Guidebooks, the CLUPs of Tacloban, Palo, Ormoc and its Master Plan, the National Building Code, the National Disaster Risk Reduction and Management Plan, the Climate Change Act, and Typhoon Haiyan government reports were reviewed.

Land use planning records in Leyte only date back from 1990s, limiting the study in terms of analysis of past land use planning DRR measures and how coastal communities sought to adapt to the impacts of extreme weather events.

\section{Climate Trends in the Philippines}

The Philippines is extremely vulnerable to the impacts of climate change and natural hazards (Lasco et al., 2009). An analysis of the climate trend done by the Philippine Atmospheric, Geophysical and Astronomical Services Administration (PAGASA, 2011) revealed that from 1951 to 2010 , there has been an increase of $0.65^{\circ} \mathrm{C}$ in annual mean temperature (Figure 1) in the Philippines.

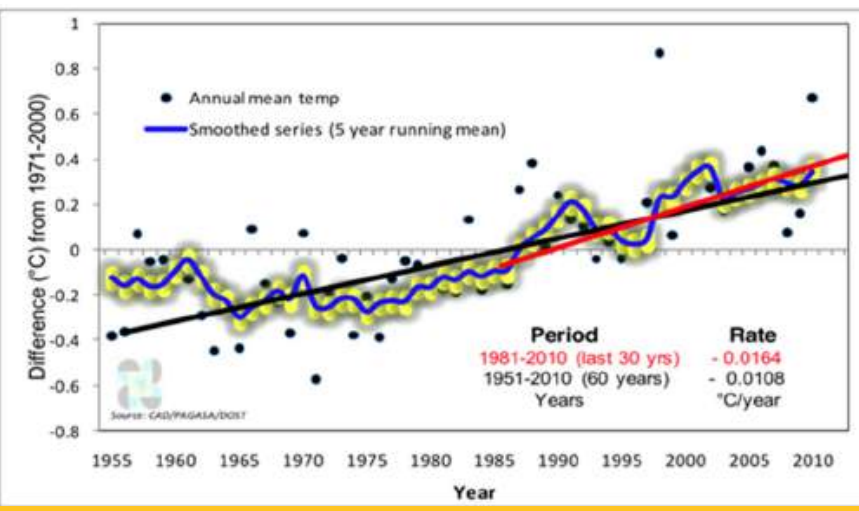

Figure 1. Observed mean temperature anomalies in the Philippines (1951-2010). Departures from 1971-2000 normal values (Cinco, 2014b).

A study by Cinco, de Guzman, Hilario, and Wilson (2014) indicated that "the climate in the Philippines, like much of the rest of the region and the globe, is warming" and potentially contribute to extreme weather events. The same study also reported that weather stations showed an increase in the frequency and intensity of extreme daily rainfall. This fact could be helpful in investigating possible links between global warming and tropical cyclones (Cinco, de Guzman, Hilario, \& Wilson, 2014).

A review by Cinco, de Guzman, Hilario, Ortiz, and Lasco (2014) indicated that every year, an average of
19.4 tropical cyclones go through the Philippine Area of Responsibility (PAR). PAGASA (2014) analyzed the tropical cyclones that entered or were formed in the PAR from 1949 to 2013 (Figure 2) and Cinco (2014a) concluded that the tropical cyclone variability in the last 66 years is still constant. Cinco (2014a) said that "there is a trend of increasing number of typhoons hitting Mindanao: the highest frequency of typhoons hitting Mindanao in the past 66 years was recorded in the last 5 years. Luzon is seeing a decreasing trend in the frequency of typhoons but it still gets the highest number of typhoons in the Philippines."

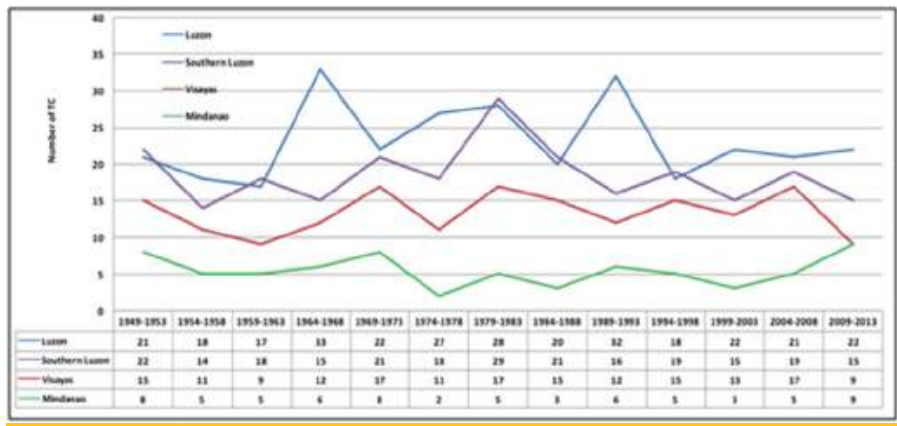

Figure 2. Five-year frequency of tropical cyclone in Luzon, Vizayas and Mindanao period: 1949-2013 (Cinco, 2014b).

Nevertheless, the trend in tropical storms (Figure 3 ) indicates that over the decades, there has been a high inter-annual variability even though there is no indication that there is an increase in frequency (PAGASA, 2014).

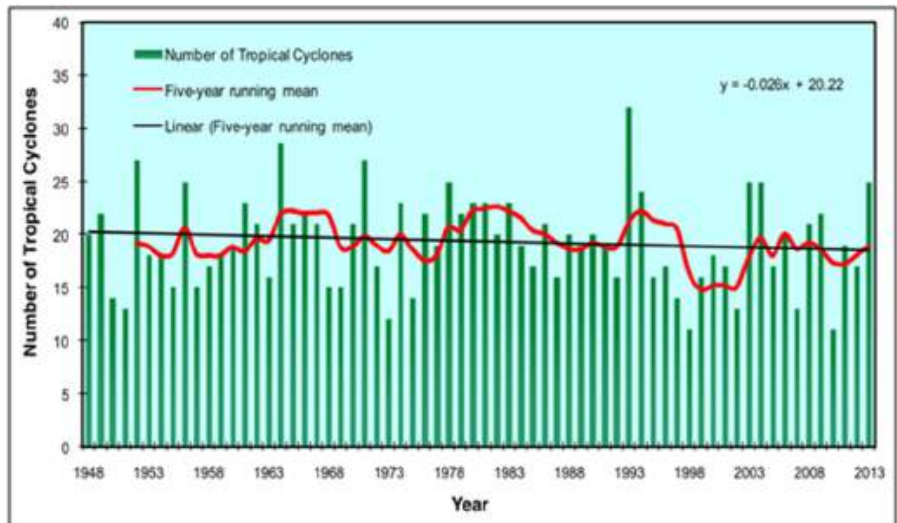

Figure 3. Annual number of tropical cyclones in the PAR period: 1948-2013 (Cinco, 2014b).

The Commissioner of the Philippines' Climate Change Commission estimated in 2013 that the impact of each tropical cyclone season cost $2 \%$ of the country's gross domestic product (GDP) and another $2 \%$ in reconstruction costs. This represents a loss of approximately $5 \%$ of the economy every year to tropical storms (Vidal, 2013), which could be used instead in development and poverty reduction efforts (Asian Development Bank [ADB], 2012; UNISDR, 2012). 


\section{Study Area}

The study sites are located along the coasts of Leyte, which over the years have experienced several climaterelated disasters. Population in these areas have been increasing, potentially enhancing the degree of exposure to hazards every year. The 2010 census data showed that the population densities of Tacloban, Palo, and Ormoc were higher than the average population density of the Philippines, with Tacloban's population density reaching as much as five times the national average.

The province of Leyte is considered a hazard prone area and $35.60 \%$ of its total population is exposed and vulnerable to weather-related hazards and seismic hazards since the area is "traversed by the Philippine Fault Zone (PFZ) and is within the vicinity of the Philippine Deep," as well as volcanic hazards (Province of Leyte, 2011, p. 41).

\section{Government Planning Before Typhoon Haiyan}

Legal and institutional framework to address climate change and disaster risk reduction and management. The enactment of the Climate Change Act of 2009 (Republic Act 9729) initiated a process aimed at mainstreaming the planning for adverse impacts of climate change into government policy formulation, development plans, strategies targeting poverty reduction, as well as other development tools and techniques.

The approval of the National Disaster Risk Reduction and Management Act of 2010 (Republic Act 10121) provided an opportunity to mainstream DRRM into development plans through the institutionalization of the National Disaster Risk Reduction and Management Plan.

The latest CLUP guidelines have been revised to comply to the mandate to mainstream CCA and DRR, with the release of the Supplemental Guidelines on Mainstreaming Climate and Disaster Risk in the CLUP (Housing and Land Use Regulatory Board, 2013, 2015).

The National Building Code. The National Building Code of the Philippines (NBCP) was approved in 1977 through the Presidential Decree 1096 (P.D. 1096). The purpose of this Code was to provide "a framework of minimum standards and requirements to regulate and control their location, site, design quality of materials, construction, use, occupancy, and maintenance" (National Building Code of the Philippines, 1977). Government agencies, including LGUs, have the authority to exceed the NBCP and promulgate stricter and more stringent standards through local laws, like zoning ordinances (National Building Code of the Philippines - NBCP, 2014).
Comprehensive Land Use Plans. In the case of the Tacloban City Government, its CLUP 2013-2022 had integrated the potential impacts of typhoons and storm surges. The CLUP referred to the susceptibility of low areas along the coast to the impact of storm surges, identifying which ones were more at risk (Tacloban City Government, 2013). However, there was probably no time to implement these measures. Given the impact of the Haiyan's storm surge, this CLUP and its accompanying zoning ordinance need to be reviewed and updated to further mainstream CCA and DRR into the planning process.

The municipality of Palo had a CLUP for the period of 2001-2010, which was due for updating (Municipality of Palo, Province of Leyte, 2001). Like Tacloban, Palo was also strongly affected by the storm surge and strong winds brought by Haiyan. The 2014 PostDisaster Redevelopment Plan will be used to initiate the update of this CLUP, which will integrate the impacts of Typhoon Haiyan as well as environment and climate change issues (Municipality of Palo, Province of Leyte, 2014).

The City of Ormoc had a CLUP (and zoning ordinance) integrated in the Master Development Plan (MDP) that ended in 2014. The MDP discussed the risks of flash floods and included geohazards, indicating the flood and earthquake-prone areas, as well as a rain-induced landslide hazard map and a tsunami hazard map (Ormoc City Government, 1998). Given that its CLUP would expire in 2014, the city initiated a process after Haiyan to review and mainstream DRR and CCA measures in the new CLUP to ensure that it would be better prepared for future extreme weather events.

Compliance with building codes. An assessment of government buildings (schools, hospitals, municipal and barangay halls as well as different public buildings) by the Department of Public Works and Highways (DPWH) found that the requirements from the building code were not rigorously followed at the local level (Office of the Presidential Assistant for Rehabilitation and Recovery [OPARR], 2014c). The key informant interviews that were conducted in the study areas provided some information about the enforcement of the building codes in these affected zones. In Tacloban, it was recognized that building codes were not enforced before Haiyan. In the municipality of Palo, a local official said that before any building construction, a location clearance must be obtained. In the City of Ormoc, local officials stated that they undertake monitoring of the structural analysis of all buildings two storeys and above.

Due to the nature of the impact of Typhoon Haiyan, the DPWH subsequently issued the Minimum Performance Standards and Specifications for public buildings, which updated "the minimum requirements in the 
design of structural elements including the increase of the wind load from $220 \mathrm{kph}$ to $250 \mathrm{kph}$. (OPARR, 2014c, p. 13).

\section{Government Planning After Typhoon Haiyan}

Reconstruction Assistance on (Haiyan) Yolanda. Immediately after Typhoon Haiyan, the Government of the Philippines started the planning process to respond to the impacts of this natural disaster by putting together the Reconstruction Assistance on Yolanda (RAY), which incorporated some of the lessons learned from the 2004 Indian Ocean tsunami.

The government would ensure that under the "Build Back Better" principle, rebuilding of public infrastructure and government buildings would consider hazard maps and would comply with resilient designs and standards. Building plans would also address hydro-meteorological risks, taking into consideration storm surges height and wind force of $250 \mathrm{kph}$, as well as ground shaking, liquefaction, and other hazards (OPARR, 2014a, 2014b, 2014c).

In the areas that were badly affected, there was a need to completely reformulate the land use plans. The process of recovery and rehabilitation is an opportunity to promote CLUPs as an instrument that "will not only provide a framework for zoning of areas for new housing but also clarify hazard zones, and areas suitable for commercial and industrial use" (NEDA, 2014).

The Post Disaster Needs Assessment. In December 2013, a Post Disaster Needs Assessment (PDNA) was undertaken to determine the costs of the damages, losses, and infrastructure needs in infrastructure across sectors in the Typhoon Haiyan affected areas (OPARR, 2014a). It also discussed the need to consider several important issues in sound DRRM practices, such as the demarcation of safe locations and hazard zones as well as strengthening of engineering standards and designs especially for critical infrastructure. Some policy issues were identified, like the urgent review of the National Building Code or strict monitoring and regular inspection to ensure compliance with building standards and designs (NDRRMC, 2014a; OPARR, $2014 \mathrm{e})$.

\section{The Comprehensive Rehabilitation and Recovery}

Plan. Zoning restrictions were imposed after Typhoon Haiyan through the application of a 40 -meter "no-build" zone policy which was based in the Presidential Decree 1067 (The Water Code of the Philippines, 1976), whose Article 51 states that "the banks of rivers and streams and the shores of the seas and lakes throughout their entire length and within a zone of three (3) meters in urban areas, twenty (20) meters in agricultural areas and forty (40) meters in forest areas, along their margins are subject to the easement of public use in the interest of recreation, navigation, floatage, fishing and salvage."

Atty. Linda Malenab-Hornilla, Commissioner of the Housing and Land Use Regulatory Board (HLURB) said in an interview that as a result of the Typhoon Haiyan storm surge, the immediate reaction was to move people away from the hazard-prone areas and prevent them from coming back and rebuilding their homes (L. Malenab-Hornilla, personal communication, September 29, 2014). This also led to an involuntary resettlement process of informal settlers to protect them from the impact of similar future events.

However, the OPARR deemed the application of the 40-meter "no-build zone" policy in the affected areas impractical, because it would not allow for the construction of any infrastructure and it would not address exceptional circumstances such as "fishing industries and tourism-oriented businesses that still need to build structures within 40 meters from the coastline" (Official Gazette of the Republic of the Philippines, 2014).

Consequently, OPARR recommended the adoption of "safe zones," "unsafe zones," and the identification of "no dwelling zones," which would be based on mapping the areas to determine the risk for each of them such as flooding or landslides. according to the OPARR proposal, under the "no dwelling zones," only structures considered for livelihoods and commercial purposes would be allowed (Official Gazette of the Republic of the Philippines, 2014).

The Comprehensive Rehabilitation and Recovery Plan (CRRP) also recommended the establishment of "safe zones," "unsafe zones," and "controlled zones" that would be based on multi-hazard risk assessments undertaken by the Department of Science and Technology (DOST) and Department of Environment and Natural Resources (DENR) together with the LGUs (OPARR, 2014e). However, it did not provide any specification in terms of the hazard zone classification and the recommended actions.

To bring more clarity into the hazard zone classification issue and to the institutional mandates as well as provide better guidance to the LGUs, a joint memorandum circular was agreed among five government agencies (DENR, DOST, DPWH, DILG, and the Department of National Defense). This joint memorandum provides guidelines for hazard zone classification and recommended activities. These are divided into hazards (floods, landslides and storm surges) and hazard zones (low, moderate and high), which would be identified according to hazards maps (DENR-DILG-DNDDPWH-DOST, 2014). 
The Typhoon Haiyan CRRP was articulated into a strategic vision and included short, medium, and long term plans and programs for the 171 cities and municipalities affected by the typhoon (OPARR, $2014 \mathrm{e})$. In terms of the shelter and land use planning sectors, the CRRP identified the following objectives: "address shelter needs including affected indigenous communities with totally damaged houses through disaster-resilient designed housing located in safe areas" as well as "strengthen disaster preparedness and mitigation by assisting local governments develop Comprehensive Land Use Plans (CLUP) with integrated disaster resiliency" (OPARR, 2014b, p. 12).

The tacloban recovery and rehabilitation plan. The Tacloban Recovery and Rehabilitation Plan was one of the provincial plans of the CRRP and it envisaged risk-sensitive land use planning, urban design, and construction as fundamental in the recovery process that would contribute towards the reduction of the impact of future disasters in this city. In the case of its land use, the update would incorporate CCA and DRR considerations in the distribution of zones of specific land uses, which will encourage development in safer areas of the city (OPARR, 2014d).

Resettlement after Haiyan. Many of the affected LGUs do not own or have available land and they do not have the titles to the land that they had identified as suitable for resettlement, but only have the tax declaration. Many municipalities also have large areas that are considered prone to geohazards, further constraining on the availability of land for resettlement (OPARR, 2014 e).

One of the biggest challenges of this process was the identification and acquisition of available and safe land for relocation and resettlement of low-income population located in hazard-prone areas. Another aspect was the willingness of the communities to move to new areas as well as the need to meet their expectations to keep their livelihoods and stay together as a community. In addition, there was always the possibility that people would return and rebuild their homes in the unsafe areas where they used to live.

\section{Discussion}

Vulnerability to typhoon-related hazards and impacts of climate change is considered to be one of the major issues affecting land use in Tacloban, Palo and Ormoc. Factors relating to vulnerability (e.g., sociodemographic characteristics, increasing poverty incidence, high population density and growth, uncontrolled development, location of informal settlements and infrastructure) could strongly influence the land use planning in these municipalities as they can drive and affect land use policies, zoning ordinances, and building regulations.
One area of concern in these study areas was the exposure of public infrastructure to the impact of Typhoon Haiyan, specifically schools because they were poorly maintained and in need of repairs. This is particularly important because of the role of public schools as evacuation centers during calamities and one of the issues raised by the respondents was the need for the government to provide safe evacuation centers.

Study respondents considered that it was fundamental to enhance the resiliency of public infrastructures to better cope with disasters especially given the poor enforcement of the building codes, which contributed to the severity of the damages by Typhoon Haiyan.

Given that one way to measure the vulnerability to natural disasters is to assess the type of housing materials and housing conditions, the people from the study areas were asked on the resilience of the building materials. Their perceptions were compared to the local officials' statement on the matter. These local government officials claimed that they provide assistance and guidance on the construction of houses. In Ormoc, structural analysis and monitoring of buildings two storeys and above is conducted to ensure that they are safe to live in. However, the majority of the respondents from Ormoc considered that the structural design of their houses was poor and needed to be improved to cope with disasters. The same was applicable to Tacloban and Palo. In addition, the majority of respondents stated that they did not receive any suggestions on the type of materials that they should use for their houses.

At the time of the survey, the application of the "nobuild zone" process was extremely contentious because many of the respondents were not aware that they were living within this zoning restriction and were told that they had to relocate.

Common trends that contribute to make the study areas more vulnerable are increasing population densities and growth rates, uncontrolled development, and increased number of informal settlements due to poverty incidence.

It is also essential to consider the importance of the bio-protection and the ecosystems services provided by the mangroves in the studied areas. These have a role to decrease vulnerability of coastal areas by potentially reducing the impact of the storm surge and protecting communities and infrastructure (Delfino et al., 2015; IPCC, 2012).

Like in the case of the 2004 Indian Ocean tsunami, the impact of Typhoon Haiyan pointed to the need to undertake hazard-based zoning. According to an interview with Atty. Antonio La Viña, Dean of Ateneo School of Government of the Ateneo de Manila 
University, the application of the Water Code provision of a 40-meter "no-build zone" was an after the fact justification with the intention to protect and prevent communities from being affected by similar future hazard events (A. La Viña, personal communication, Oct. 3, 2014). Nonetheless, the applicability of the 40-meter "no-build zone" should have been restricted to forest areas, in accordance with the Water Code, and yet was enforced outside them. In addition, this application could have been interpreted as confiscatory with potential intention to expropriate and also as an encroachment into private property rights (L. MalenabHornilla, personal communication, September 29, 2014).

This decision should be done based on local risk analysis followed by a vulnerability assessment, which should then lead to policy recommendations (A. La Viña, personal communication, October 3, 2014). It is also important from an institutional point of view to understand who would be responsible for its implementation both at central and local level and to have more guidance on its implementation (e.g., the CLUP). Nevertheless, according to Atty. MalenabHornilla, in terms of performance-based zoning, structures and activities should be allowed as long as they follow the safety building standards set by the national government. These standards may be set higher by LGUs but not lower.

However, the OPARR/CRRP recommendation, the subsequent joint memorandum on hazard zone classification, and the recent CLUP guidelines on the zoning policy can potentially be confusing and daunting for the local planners in terms of the correct zoning to plan and apply.

Even though the zoning for hazards classification approach is similar, it would be useful for LGUs to have just one set of zoning for hazards classification (i.e. CLUP guidelines) not only for typhoon affected areas but also nationally. Some of the suggested guidance may require a level of capacity that LGUs may lack, which could potentially delay the designation of hazard prone areas and zoning ordinances. Nevertheless, this issue could be addressed through partnerships to help address any capacity limitations. Despite these issues, land use planning, implementation of building codes, and retrofitting can be very effective to enhance CCA and DRR and therefore should not be ignored.

In 2014, a plan was approved to build a dike that will be 4 meters high above sea level to protect Tacloban, Palo, and Tanauan from storm surges. Building a 27-kilometer dike right after Haiyan to defend coastal areas from storm surge with flood return periods of 50 years could potentially be seen as a costly defense mechanism if no other options were discussed and experiences from other countries taken into consideration.

\section{Conclusion and Recommendations}

In the wake of Typhoon Haiyan, one key learning point is that it is imperative to reduce the potential risks of extreme weather events and ensure long-term resilience of people and infrastructures by seriously investing on and implementing risk-sensitive land use planning and instruments like zoning, building codes, and retrofitting of vulnerable buildings. However, these measures need to be properly implemented and supported by strong political commitment. Additionally, risk reduction actions in the context of land use planning should combine regulatory measures with innovative financial incentives.

Local governments should actively anticipate the impacts of extreme climate events and seek opportunities to enhance the planning process in terms of DRR and CCA. In addition, local decision making should incorporate risk assessment and the identification of hazards, and how it affects land use and physical framework planning.

Another policy for risk reduction that should be taken into consideration by LGUs, particularly when defining the zones in their CLUPs, is designating mangrove conservation, preservation, and rehabilitation areas to protect the coastline. These natural buffer areas should be increased to enhance the resilience of coastal communities to tropical cyclones and storm surges.

One essential lesson to take is the need for LGUs to avoid implementing no build zones as a reactive measure to the impact of tropical cyclones without undertaking vulnerability and risk assessments in support of their hazard zone classification.

It is also important to undertake monitoring and evaluation to assess the impacts of the rehabilitation and recovery process in the resilience of communities in the Typhoon Haiyan affected areas.

The social vulnerability assessment is one way to mainstream CCA and DRR issues into local policies and plans. The CLUP process should take this aspect into consideration in the identification of sensitivities, exposures, and adaptive capacities into development planning.

An issue that should be taken into consideration is ensuring the use of technical knowledge such as the national and regional climate projections and geohazards information in local decision making. Given the adaptation capacity needs of local governments, generating partnerships with the scientific community, non-governmental organizations, and the private sector to address knowledge gaps in land use planning is critical. 
To enable the LGUs approaches promoting community resilience, planning processes should encourage public participation and should take place before disasters hit. This has to be followed by making hazard, vulnerability, and risk information readily available to the public (e.g., maps). LGUs should also exceed the standards set by the national government, such as the building code, based on their particular climate and hazard conditions. As such, LGUs should apply, enforce, and monitor realistic risk-compliant building regulations.

To further advance this matter, LGUs should consider improving the information dissemination to the communities on the services that they can provide regarding guidance on the structural design and construction of houses. LGUs should consider approaches such as resilient housing design that follow safety-building standards strictly enforced, and based on geohazard maps. The same is applicable to recommendations on the adequate type of materials that should be used to resist the impacts from typhooninduced hazards such as storm surges, flooding, and strong winds. To address potential capacity gaps, LGUs could partner with professional organizations such as the Philippines Institute of Civil Engineering or the Association of Structural Engineers of the Philippines.

Lessons learned from the Haiyan experience should be integrated not only in Haiyan-affected areas but also in CLUPs in other areas of the country, particularly when contextualizing with the updated CLUP guidelines. These can be effective long-term planning instruments to improve climate resilience by mainstreaming DRR and CCA measures in development planning, particularly at local level and duly implemented.

Lastly, future research should be undertaken in these typhoon-affected areas to study the reasons for poor compliance of building standards and designs of both public and private infrastructures in hazard prone areas.

\section{References}

Asian Development Bank. (2012). Addressing Climate Change and Migration in Asia and the Pacific. Asian Development Bank. Retrieved from http://www.adb.org/ publications/addressing-climate-change-and-migrationasia-and-pacific

Chughtai, S. (2013). Typhoon Haiyan, The response so far and vital lessons for the Philippines Recovery (Oxfam Briefing Note). UK: Oxfam International. Retrieved from https://www.oxfam.org/sites/www.oxfam.org/ files/bn-typhoon-haiyan-philippines-response-071213en.pdf
Cinco, T. A. (2014a, April). Severe Risk Modeling. Presented at the Technical Workshop on Holistic Response to the Need for Resilient Low-Cost Housing, Oracle Hotel, Quezon City. Retrieved from http://essc.org. $\mathrm{ph} / \mathrm{content/wp-content/uploads/2014/04/Report}$ TechnicalWorkshop_2_3April2014.pdf

Cinco, T. A. (2014b, August). Understanding Past and Future Climate (Climate Change Scenario for the Philippines). Presented at the OML Center Workshop on Translating Climate and Disaster Information for Effective Decision-Making, Richmonde Hotel, Ortigas Center, Pasig City. Philippines.

Cinco, T. A., de Guzman, R. G., Hilario, F. D., Ortiz, A. M. D., \& Lasco, R. D. (2014). Climatology of Tropical Cyclones in the Philippines.

Cinco, T. A., de Guzman, R. G., Hilario, F. D., \& Wilson, D. M. (2014). Long-term trends and extremes in observed daily precipitation and near surface air temperature in the Philippines for the period 1951-2010. Atmospheric Research, 145-146, 12-26. http://doi.org/doi:10.1016/j. atmosres.2014.03.025

Climate Change Act of 2009, Republic Act 9729 (2009).

Costa, J. P. (2011). Urbanismo ea Adaptação às Alterações Climáticas. As Frentes de Água. In Climate Proof Cities (p. 218). Lisbon, Portugal: Universidade Técnica de Lisboa.

Delfino, R. J. P., Carlos, C. M., David, L. T., Lasco, R. D., \& Juanico, D. E. (2015). Perceptions of Typhoon Haiyan affected communities about the resilience and storm protection function of mangrove ecosystems in Leyte and Eastern Samar, Philippines. Climate, Disaster and Development Journal, 1(1), 1-8.

Housing and Land Use Regulatory Board. (2013). A Guide to Land Use Plan Preparation.Volume 1. The Planning Process. Republic of the Philippines.

Housing and Land Use Regulatory Board. (2015). Supplemental Guidelines on Mainstreaming Climate and Disaster Risks in the Comprehensive Land Use Plan. Republic of the Philippines.

IPCC. (2012). Managing the risks of extreme events and disasters to advance climate change adaptation. A special report of Working Groups I and II to the Intergovernmental Panel on Climate Change. (C. B. Field, V. Barros, T. F. Stocker, Q. Dahe, D. J. Dokken, K. L. Ebi, ... P. M. Midgley, Eds.). Cambridge, UK and New York, NY, USA: Cambridge University Press. 
IPCC. (2014a). Climate Change 2014: Impacts, Adaptation, and Vulnerability. Part A: Global and Sectoral Aspects. Contribution of Working Group II to the Fifth Assessment Report of the Intergovernmental Panel on Climate Change. (C. B. Field, V. R. Barros, D. J. Dokken, K. J. Mach, M. D. Mastrandrea, T. E. Bilir, ... L. L. White, Eds.). Cambridge, United Kingdom and New York, NY, USA: Cambridge University Press.

IPCC. (2014b). Climate Change 2014: Synthesis Report. Contribution of Working Groups I, II and III to the Fifth Assessment Report of the Intergovernmental Panel on Climate Change. (Core Writing Team, R. K. Pachauri, \& L. A. Meyer, Eds.). Geneva, Switzerland: Intergovernmental Panel on Climate Change.

Joint DENR-DILG-DND-DPWH-DOST Memorandum Circular. Adoption of hazard zone classification in areas affected by Typhoon Yolanda (Haiyan) and providing guidelines for activities therein. (2014).

Lasco, R. D., Pulhin, F. B., Jaranilla-Sanchez, P. A., Delfino, R. J. P., Gerpacio, R., \& Garcia, K. (2009). Mainstreaming adaptation in developing countries: The case of the Philippines. Climate and Development, 1(2), 130-146. http://doi.org/10.3763/cdev.2009.0009

Mullen, J. (2013, November 8). Super Typhoon Haiyan, strongest storm of 2013, hits Philippines - CNN.com. Retrieved December 18, 2015, from http://www.cnn. com/2013/11/07/world/asia/philippines-typhoonhaiyan/index.html

Municipality of Palo, Province of Leyte. (2001). Comprehensive Land Use Plan 2001-2010.

Municipality of Palo, Province of Leyte. (2014). Redevelopment Plan. Grandt Planners, Inc.

National Building Code of the Philippines, Presidential Decree 1096 (1977).

National Building Code of the Philippines - NBCP. (2014, November 9). The LGU Office of the Building Official (OBO) can actually impose a lower building height limit (BHL) for any LGU zoning classification provided... [Facebook status update]. Retrieved from https://www.facebook.com/BuildingCode.Ph/ posts/943239319020308

National Disaster Risk Reduction and Management Act of 2010, Republic Act 10121 (2010).
NDRRMC. (2014a). Post Disaster Needs Assessment in TY Yolanda Affected Areas. Quezon City, Philippines: National Disaster Risk Reduction and Management Council. Retrieved from http://www.ndrrmc.gov. ph/attachments/article/1329/Effects_of_Typhoon_ YOLANDA_(HAIYAN)_SitRep_No_108_03APR2014. pdf

NDRRMC. (2014b). SitRep No. 108, Effect of Typhoon "Yolanda" (Haiyan) (NDRRMC Update). Quezon City, Philippines: National Disaster Risk Reduction and Management Council. Retrieved from http:// www.ndrrmc.gov.ph/attachments/article/1329/ Effects_of_Typhoon_YOLANDA_(HAIYAN)_SitRep_ No_108_03APR2014.pdf

NDRRMC. (2014c). Updates, Situation Report, the Effects of Typhoon "Yolanda" (Haiyan) (NDRRMC Update). Quezon City, Philippines: National Disaster Risk Reduction and Management Council. Retrieved from http://www.ndrrmc.gov.ph/attachments/article/1329/ Update_on_Effects_Typhoon_YOLANDA_ (Haiyan)_17APR2014.pdf

NEDA. (2013). Reconstruction Assistance on Yolanda: BuildBack-Better (p. 21). National Economic and Development Authority. Retrieved from http://yolanda. neda.gov.ph/reconstruction-assistance-on-yolanda-raybuild-back-better/

NEDA. (2014). Reconstruction Assistance on Yolanda: Implementation for Results (p. 43). National Economic and Development Authority. Retrieved from http:// yolanda.neda.gov.ph/reconstruction-assistance-onyolanda-ray-implementation-for-results/

Office of the Presidential Assistant for Rehabilitation and Recovery. (2014a). Comprehensive Rehabilitation and Recovery Plan.

Office of the Presidential Assistant for Rehabilitation and Recovery. (2014b). Comprehensive Rehabilitation and Recovery Plan. Annex A: Social Services Plan.

Office of the Presidential Assistant for Rehabilitation and Recovery. (2014c). Comprehensive Rehabilitation and Recovery Plan. Annex B: Infrastructure Cluster Plan.

Office of the Presidential Assistant for Rehabilitation and Recovery. (2014d). Comprehensive Rehabilitation and Recovery Plan. Annex E: Provincial Plans.

Office of the Presidential Assistant for Rehabilitation and Recovery. (2014e). Yolanda Rehabilitation and Recovery Efforts [Brochure]. 
Official Gazette of the Republic of the Philippines. (2014, March 14). PARR: "No Build Zone" Policy not recommended in Yolanda-affected areas. Retrieved December 19, 2015, from http://www. gov.ph/2014/03/14/parr-no-build-zone-policy-notrecommended-in-yolanda-affected-areas/

Ormoc City Government. (1998). Ormoc City Master Development Plan/Comprehensive Land Use Plan, Final Report.

PAGASA. (2011, February). Climate Change in the Philippines. Philippine Atmospheric, Geophysical and Astronomical Services Administration. Retrieved from http://kidlat.pagasa.dost.gov.ph/cab/climate_change/ Climate\%20change \%20in\%20the\%20Philippines\%20 -\%20August $\% 2025 \% 202011$.pdf

PAGASA. (2014). Current Climate and Observed Trends. Retrieved from http://www.pagasa.dost.gov.ph/climateagromet/climate-change-in-the-philippines/116climate-change-in-the-philippines/594-current-climateand-observed-trends

Province of Leyte. (2011). Disaster Risk Reduction Climate Change Adaptation-Enhanced Provincial Development and Physical Framework Plan 2011-2016. Provincial Planning and Development Office, Province of Leyte.

Rappaport, E. N. (2000). Loss of Life in the United States Associated with Recent Atlantic Tropical Cyclones. Bulletin of the American Meteorological Society, 81 (9), 2065-2073. http://doi.org/10.1175/15200477(2000)081<2065:LOLITU>2.3.CO;2

Sutanta, H., Rajabifard, A., \& Bishop, I. (2010). Integrating spatial planning and disaster risk reduction at the local level in the context of spatially enabled government. Retrieved from https://minerva-access.unimelb.edu.au/ handle/11343/28949

Tacloban City Government. (2013). The Comprehensive Land Use Plan for 2013-2022.

The Water Code of the Philippines, Presidential Decree No. 1067 (1976). Retrieved from http://www.gov. ph/1976/12/31/presidential-decree-no-1067-s-1976/

UNISDR. (2012, December 5). Philippines early warning system saves lives as thousands flee Typhoon Bopha. Retrieved from http://www.unisdr.org/archive/29954

UNOCHA. (2013, November 12). Philippines: Typhoon Haiyan Action Plan - November 2013. Retrieved from http://www.unocha.org/cap/appeals/philippinestyphoon-haiyan-action-plan-november-2013
Vidal, J. (2013, November 8). Typhoon Haiyan: what really alarms Filipinos is the rich world ignoring climate change. The Guardian. Retrieved from http://www. theguardian.com/commentisfree/2013/nov/08/typhoonhaiyan-rich-ignore-climate-change

World Bank. (2014). Pursuing Inclusive Growth through Sustainable Reconstruction and Job Creation. Poverty Reduction and Economic (Philippine Economic Update). Poverty Reduction and Economic Management Unit, Philippine Country Office East Asia and Pacific Region, World Bank. 